\title{
Identification of lactobacilli by pheS and rpoA gene sequence analyses
}

\author{
Correspondence \\ Sabri M. Naser \\ Sabri-Naser@najah.edu
}

\author{
Sabri M. Naser, ${ }^{1}$ Peter Dawyndt, ${ }^{2,4}$ Bart Hoste, $^{3}$ Dirk Gevers, ${ }^{2,5}$ \\ Katrien Vandemeulebroecke, ${ }^{3}$ Ilse Cleenwerck, ${ }^{3}$ Marc Vancanneyt ${ }^{3}$ \\ and Jean Swings 2,3
${ }^{1}$ Department of Biology and Biotechnology, Faculty of Sciences, An-Najah National University, Nablus, Palestine
${ }^{2}$ Laboratory of Microbiology, Ghent University, K.L. Ledeganckstraat 35, Ghent 9000, Belgium
${ }^{3} \mathrm{BCCM}^{\mathrm{TM}}$ /LMG Bacteria Collection, Ghent University, K.L. Ledeganckstraat 35, Ghent 9000, Belgium
${ }^{4}$ Department of Applied Mathematics, Biometrics and Process Control, Ghent University, Coupure links 653, Ghent 9000, Belgium
${ }^{5}$ Bioinformatics and Evolutionary Genomics, Ghent University/VIB, Technologiepark 927, Ghent 9052, Belgium

\section{INTRODUCTION}

Lactic acid bacteria (LAB) belonging to the genus Lactobacillus comprise the largest group of Gram-positive, rod-shaped and catalase-negative organisms (Hammes \& Vogel, 1995) with Lactobacillus delbrueckii as the type

Abbreviations: FAFLP, fluorescent amplified fragment length polymorphism; LAB, lactic acid bacteria; OTU, operational taxonomic unit.

The GenBank/EMBL/DDBJ accession numbers for the sequences reported in this paper are AM087677-AM087773, AM263502AM263510, AM157783-AM157787, AM168426-AM168429, AM159098-AM159099, AM236139-AM236143, AM284176AM284250, AM694185, AM694187 (pheS partial gene sequences) and AM087774-AM087869, AM263511-AM263518, AM157775, AM157777-AM157780, AM168431-AM168433, AM236144AM236148, AM284251-AM284315, AM694186, AM694188 (rpoA partial gene sequences).

Neighbour-joining phylogenetic trees constructed using the pheS and rpoA gene sequences of the type strains of species of the genus Lactobacillus are available with the online version of this paper. species (Kandler \& Weiss, 1986). Species of the genus Lactobacillus form part of the normal flora of the gastrointestinal tract, vagina and oral cavity of humans and animals (Hammes \& Vogel, 1995; Klein et al., 1998). Lactobacilli are of great economic importance for the dairy and other fermented food industries, where they are used as starter cultures for fermenting raw materials of vegetable or animal origin. Lactobacillus species are claimed to have health-promoting (probiotic) properties and some pharmaceutical preparations contain viable Lactobacillus strains (Holzapfel et al., 2001; Reid, 1999; Stiles \& Holzapfel, 1997). In this context, the accurate identification of members of the genus Lactobacillus remains a point of crucial importance.

Several methods have been used for the identification of lactobacilli to the species level, e.g. SDS-PAGE of wholecell proteins, randomly amplified polymorphic DNA (RAPD), amplified fragment length polymorphism (AFLP), rep-PCR and ribotyping (Daud Khaled et al., 
1997; Gancheva et al., 1999; Gevers et al., 2001; Massi et al., 2004; Pot et al., 1993; Yansanjav et al., 2003). Although useful, there are some pitfalls associated with the use of these methods concerning portability, inter-laboratory reproducibility and time efficacy. Informational genes such as the $16 \mathrm{~S}$ rRNA gene are commonly considered as reliable phylogenetic markers for assigning evolutionary relationships among species of the genus Lactobacillus (Schleifer \& Ludwig, 1995). However, 16 S rRNA gene sequence data do not allow the identification of closely related species. The use of housekeeping genes is emerging as an alternative to overcome these problems (Santos \& Ochman, 2004; Stackebrandt et al., 2002). Recent in silico studies based on complete genomes have provided the basis for establishing sets of housekeeping genes that can accurately predict genome relatedness and improve the accuracy of species identification. The need for alternative genomic markers that provide higher levels of discrimination than the 16S rRNA gene has led to a more systematic sequencing of housekeeping genes (Coenye et al., 2005; Gevers et al., 2005; Konstantinidis \& Tiedje, 2005; Naser et al., 2005a, b; Thompson et al., 2005; Zeigler, 2003).

To be useful for species discrimination, genes must ideally be present in a single copy, evolve more rapidly than rRNA genes and be widely distributed among bacterial genomes. Those genes in which recombination might confer a selective advantage, or closely linked genes, should be avoided. Furthermore, these genes should be informative with an adequate degree of resolution and provide sufficient variability to differentiate species of a particular genus (Zeigler, 2003).

The use of the housekeeping genes that code for the $\alpha$ subunit of bacterial phenylalanyl-tRNA synthase (pheS) and the $\alpha$-subunit of RNA polymerase ( $r p o A)$ has proven to be a robust system for the identification of all the recognized species of the genus Enterococcus (Naser et al., $2005 \mathrm{~b}$ ). As it is our intention to extend the application of these protein-coding loci to all other LAB genera, the present study was aimed at evaluating the usefulness of pheS and rpoA gene sequences as alternative genomic tools for the identification of species of the genus Lactobacillus. We compared the sequence data of the pheS and rpoA genes with the available 16S rRNA gene sequences. In addition, a software tool, named TaxonGap, was developed during this study to enable a straightforward evaluation of the discriminatory power of the individual genes in the Lactobacillus identification scheme.

\section{METHODS}

Two hundred and one well-characterized Lactobacillus strains representing 98 species and 17 subspecies of the genus Lactobacillus isolated from humans, animals or food products were analysed in this study (Table 1). Strains were grown on MRS agar media (Oxoid) at $37{ }^{\circ} \mathrm{C}$ for $48 \mathrm{~h}$. All strains included in this study have been deposited in the BCCM/LMG Bacteria Collection at Ghent University (Ghent, Belgium). Bacterial genomic DNA was extracted as described by
Gevers et al. (2001) or DNA alkaline extract was used (Niemann et al., 1997). The amplification and sequencing of pheS and rpoA genes were as described by Naser et al. (2005a, b) with the following modifications: where an amplicon was not obtained with the referred conditions, the primer combination rpoA-21-F/rpoA-22-R (5'ATGATYGARTTTGAAAAACC-3' $/ 5^{\prime}$-ACYTTVATCATNTCWGVYTC-3') was used for the amplification of the $r p o A$ gene and/or the Failsafe PCR system (Epicenter).

Consensus sequences were determined as described by Naser et al. (2005a, b). The CLUSTAL_x program was used for multiple sequence alignment. Consequently, the aligned sequences were imported into BioNumerics software version 4.5 (Applied Maths) for the calculation of similarity matrices and neighbour-joining trees (Saitou \& Nei, 1987). The reliability of hierarchical clustering was determined by using the bootstrapping method with 1000 resamplings. The 16S rRNA gene sequence data of the Lactobacillus type strains were obtained from EMBL.

TaxonGap software tool. When evaluating multiple genes as candidate biomarkers for the identification of different operational taxonomic units (OTUs) (Sneath \& Sokal, 1973), one is intuitively looking for molecular markers that show the least amount of heterogeneity within OTUs and also result in maximal separation between the different OTUs. The first requirement must guarantee that members of the same OTU have the same (or at least similar) biomarkers, so that they can easily be grouped together based on those markers. The second requirement is that members of different OTUs must have sufficiently different biomarkers so that an evaluation of these markers cannot erroneously suggest assignment of the members to the same OTU. The TaxonGap software tool was specially designed to produce a compact representation of the resolution of the biomarkers within and between taxonomic units, allowing easy and reliable inspection of the data for evaluations across the different OTUs and the different biomarkers.

For a given set of OTUs $O_{1}, O_{2}, \ldots, O_{n}$, the $s$-heterogeneity within the taxon $O_{i}(i=1, \ldots, n)$ is defined as $\max _{x, y \in O i, x \neq y} d_{s}(x, y)$. Herein, $d_{s}$ $(x, y)$ represents the distance between the (different) members $x$ and $y$ of the taxon $O_{i}$ as measured from the biomarker $s$. Likewise, the $s$ separability of the taxon $O_{i}(i=1, \ldots, n)$ is defined as $\min _{x \in O i, y \notin O i}$ $d_{s}(x, y)$. The taxon containing $y$, for which the minimum distance is reached during the calculation of the s-separability, is called the closest neighbour of the taxon $O_{i}$. Note, however, that the closest neighbour relationship is not necessarily symmetric; given that $O_{i}$ is the closest neighbour of $O_{j}$, it does not automatically follow that $O_{j}$ is also the closest neighbour of $O_{i}$. The calculation of the $s$-heterogeneity and the $s$-separability are schematically represented in Fig. 1 for a taxon $\mathrm{A}$ and its closest neighbouring taxon $\mathrm{B}$.

The TaxonGap software tool calculates the matrix of $s$-heterogeneity and $s$-separability values with the different OTUs as the matrix rows and the different biomarkers as the matrix columns. Headers are placed to the left and on top of the matrix. The rows and columns of the matrix can be placed in any order. However, to improve interpretability of the resulting representation, we have included the option to present the OTUs according to their position in a phylogenetic tree as an alternative to listing them in alphabetical order. Again, with the aim of improving the visual inspection and interpretation of the data, the TaxonGap software tool presents the $s$ heterogeneity and $s$-separability values as light grey and dark grey horizontal bars, respectively. The same scaling is used for plotting the $s$-heterogeneity and $s$-separability bars for the individual biomarkers in order to support optimal comparability of the values across the biomarkers. The name of the closest neighbour is attached to the right side of the dark grey bar. Light grey bars are printed on top of the dark grey bars and are made slightly thinner than the dark grey bars to improve visualization even when the light bars grow larger than the 
Table 1. Details of the Lactobacillus species and strains that were analysed in this study

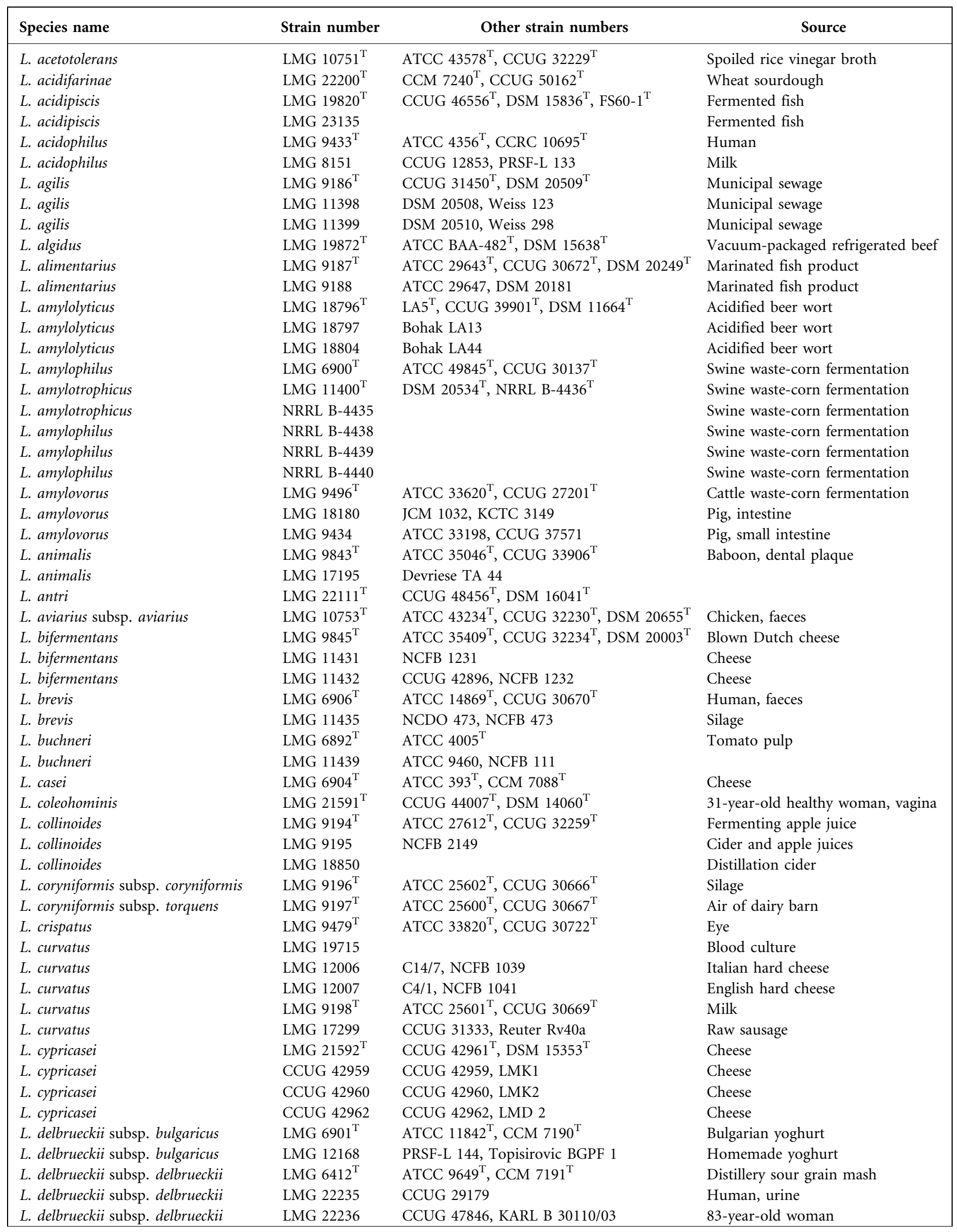


Table 1. cont.

\begin{tabular}{|c|c|c|c|}
\hline Species name & Strain number & Other strain numbers & Source \\
\hline L. delbrueckii subsp. indicus & LMG $22083^{\mathrm{T}}$ & DSM $15996^{\mathrm{T}}, \mathrm{NCC} 725^{\mathrm{T}}$ & Indian diary products \\
\hline L. delbrueckii subsp. lactis & LMG $7942^{\mathrm{T}}$ & ATCC $12315^{\mathrm{T}}$, CCUG $31454^{\mathrm{T}}$ & Emmental cheese \\
\hline L. delbrueckii subsp. lactis & LMG 6401 & ACM 3573, ATCC 7830 & \\
\hline L. diolivorans & LMG $19667^{\mathrm{T}}$ & DSM $14421^{\mathrm{T}}, \mathrm{JCM} 12183^{\mathrm{T}}$ & Maize silage \\
\hline L. durianis & LMG $19193^{\mathrm{T}}$ & CCUG $45405^{\mathrm{T}}$, CIP $107501^{\mathrm{T}}$, DSM $15802^{\mathrm{T}}$ & Tempoyak \\
\hline L. durianis & LMG 19196 & MC13-1 & Tempoyak \\
\hline L. equi & LMG $21748^{\mathrm{T}}$ & CCUG $47129^{\mathrm{T}}$, DSM $15833^{\mathrm{T}}$ & Horse, faeces \\
\hline L. farciminis & LMG $9200^{\mathrm{T}}$ & ATCC $29644^{\mathrm{T}}$, CCUG $30671^{\mathrm{T}}$, DSM $20184^{\mathrm{T}}$ & Sausage \\
\hline L. farciminis & LMG 17703 & Leisner II-8-50 & Marinated meat product \\
\hline L. fermentum & LMG $6902^{\mathrm{T}}$ & ATCC $14931^{\mathrm{T}}$, CCM $7192^{\mathrm{T}}$ & Fermented beets (Beta vulgaris) \\
\hline L. fermentum & LMG 8902 & CCM 2481, NCFB 2341 & \\
\hline L. fermentum & LMG 8154 & CCUG 2231, La45 & \\
\hline L. fructivorans & LMG $9201^{\mathrm{T}}$ & ATCC $8288^{\mathrm{T}}$, DSM $20203^{\mathrm{T}}$ & \\
\hline L. fructivorans & LMG 9202 & NCFB 2166, NCIMB 5223, strain W1 & \\
\hline L. frumenti & LMG $19473^{\mathrm{T}}$ & DSM $13145^{\mathrm{T}}$, TMW $1.666^{\mathrm{T}}$ & Rye-bran sourdough \\
\hline L. fuchuensis & LMG $21669^{\mathrm{T}}$ & CCUG $47133^{\mathrm{T}}$, DSM $14340^{\mathrm{T}}$ & Vacuum-packaged refrigerated beef \\
\hline L. gallinarum & LMG $9435^{\mathrm{T}}$ & ATCC $33199^{\mathrm{T}}$, CCUG $30724^{\mathrm{T}}$, DSM $10532^{\mathrm{T}}$ & Chicken, crop \\
\hline L. gallinarum & LMG 14751 & CCUG 31412, Fujisawa T-50, JCM 8782 & Chicken, faeces \\
\hline L. gallinarum & LMG 14755 & Fujisawa TFC3, JCM 8786 & Chicken, faeces \\
\hline L. gasseri & LMG $9203^{\mathrm{T}}$ & ATCC $33323^{\mathrm{T}}$, CCUG $31451^{\mathrm{T}}$ & Human \\
\hline L. gasseri & LMG 13134 & ATCC 9857, CIP 62.18 & Vaginal tract \\
\hline L. gasseri & LMG 11413 & NCIMB 8819, PRSF-L 146 & Human, saliva \\
\hline L. gasseri & LMG 18176 & JCM 1025, PRSF-L 150 & Human, intestine \\
\hline L. gasseri & LMG 10771 & CCUG 25736 & Wine \\
\hline L. gasseri & LMG 13047 & ATCC 19992, CCUG 39972, DSM 20077 & Human, faeces \\
\hline L. gasseri & LMG 18177 & JCM 1026 & \\
\hline L. gasseri & LMG 11478 & ATCC 4963, JCM 5343 & Human \\
\hline L. gastricus & LMG $22113^{\mathrm{T}}$ & CCUG $48454^{\mathrm{T}}, \mathrm{DSM} 16045^{\mathrm{T}}, \mathrm{Kx} 156 \mathrm{~A} 7^{\mathrm{T}}$ & Human stomach mucosa \\
\hline L. graminis & LMG $9825^{\mathrm{T}}$ & ATCC $51150^{\mathrm{T}}$, CCUG $32238^{\mathrm{T}}$ & Grass silage \\
\hline L. hammesii & LMG $23074^{\mathrm{T}}$ & & French wheat sourdough \\
\hline L. hamsteri & LMG $10754^{\mathrm{T}}$ & ATCC $43851^{\mathrm{T}}$, DSM $5661^{\mathrm{T}}$ & Hamster, faeces \\
\hline L. helveticus & LMG $6413^{\mathrm{T}}$ & ATCC $15009^{\mathrm{T}}$, BCRC $12936^{\mathrm{T}}$, CCM $7193^{\mathrm{T}}$ & Swiss Emmental cheese \\
\hline L. helveticus & LMG 11445 & ATCC 521, BCRC 14026, CCM 1751 & \\
\hline L. helveticus & LMG 11447 & ATCC 10812, BCRC 14021 & \\
\hline L. helveticus & LMG 13522 & ATCC 12046, BCRC 12259, JCM 1554 & \\
\hline L. helveticus & LMG 18225 & ATCC 8001, NCFB 103 & \\
\hline L. helveticus & LMG 22464 & $\begin{array}{l}\text { CCUG 50205, SA, type strain of } \\
\text { L. suntoryeus }\end{array}$ & Malt whisky fermentation \\
\hline L. helveticus & LMG 22465 & M4 & Malt whisky fermentation \\
\hline L. hilgardii & LMG $6895^{\mathrm{T}}$ & ATCC $8290^{\mathrm{T}}$, CCUG $30140^{\mathrm{T}}$ & Wine \\
\hline L. hilgardii & LMG 11964 & CECT 4681, Couto 28 & Port wine \\
\hline L. hilgardii & LMG 11966 & CECT 4682, Couto 30 & Port wine machinery \\
\hline L. homohiochii & LMG $9478^{\mathrm{T}}$ & ATCC $15434^{\mathrm{T}}$, CCUG $32247^{\mathrm{T}}$, DSM $20571^{\mathrm{T}}$ & Spoiled sake \\
\hline L. iners & LMG $18914^{\mathrm{T}}$ & CCUG $28746^{\mathrm{T}}$, DSM $13335^{\mathrm{T}}$ & 36-year-old woman, urine \\
\hline L. iners & LMG 18915 & CCUG 37287, strain 8 & Medical care product \\
\hline L. iners & LMG 18916 & CCUG 38673 & Healthy 28-year-old woman, cervix \\
\hline L. ingluviei & LMG $20380^{\mathrm{T}}$ & CCUG $45722^{\mathrm{T}}, \mathrm{KR}^{\mathrm{T}}, \mathrm{JCM} 12531^{\mathrm{T}}$ & Pigeon, crop \\
\hline L. ingluviei & LMG 22056 & DSM 14792 , type strain of $L$. thermotolerans & Chicken, faeces \\
\hline L. intestinalis & LMG $14196^{\mathrm{T}}$ & ATCC $49335^{\mathrm{T}}$, CCUG $30727^{\mathrm{T}}$, DSM $6629^{\mathrm{T}}$ & Rat, intestine \\
\hline L. intestinalis & LMG 11462 & NCFB 2176, strain HE1 & \\
\hline L. jensenii & LMG $6414^{\mathrm{T}}$ & ATCC $25258^{\mathrm{T}}$, BCRC $12939^{\mathrm{T}}$ & Human, vaginal discharge \\
\hline L. johnsonii & LMG $9436^{\mathrm{T}}$ & ATCC $33200^{\mathrm{T}}$, CCUG $30725^{\mathrm{T}}$, DSM $10533^{\mathrm{T}}$ & Human, blood \\
\hline L. johnsonii & LMG 18206 & CCUG 31413, JCM 8793 & Pig, faeces \\
\hline L. johnsonii & LMG 9437 & ATCC 11506 & \\
\hline L. johnsonii & LMG 11468 & ATCC 332, CCUG 44520 & Human \\
\hline L. johnsonii & LMG 18175 & JCM 1022, PRSF-L 156 & Human, intestine \\
\hline L. johnsonii & LMG 18193 & CCRC 14037, JCM 5812, PRSF-L 154 & Pharmaceutical preparation \\
\hline
\end{tabular}


Table 1. cont.

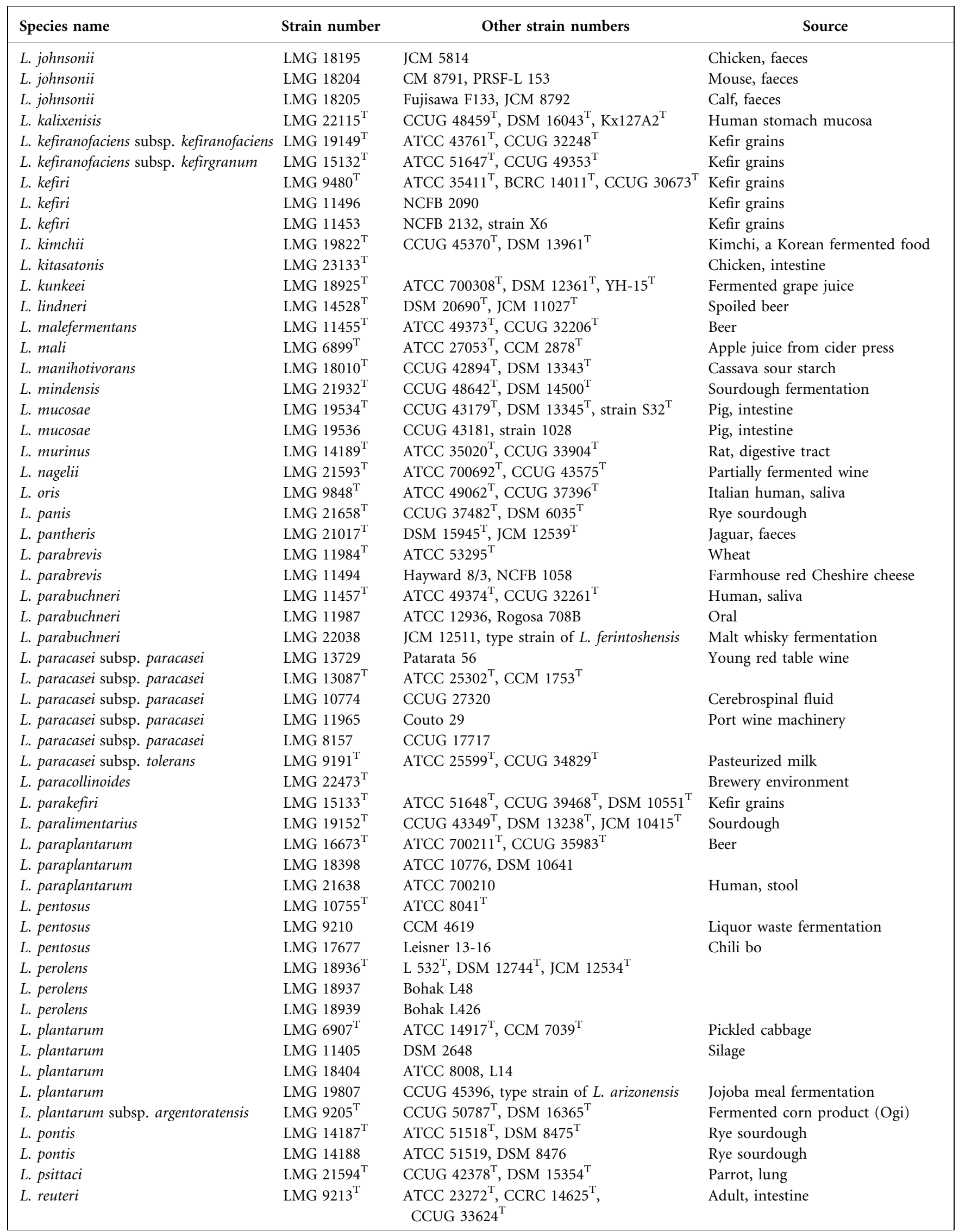


Table 1. cont.

\begin{tabular}{|c|c|c|c|}
\hline Species name & Strain number & Other strain numbers & Source \\
\hline L. reuteri & LMG 18238 & ATCC 55148, Bio Gaia AB 11284 & Chicken \\
\hline L. reuteri & LMG 13090 & CCUG 42759, PRSF-L 164, strain A1 & Rat \\
\hline L. rhamnosus & LMG $6400^{\mathrm{T}}$ & ACM $539^{\mathrm{T}}$, ATCC $7469^{\mathrm{T}}$ & \\
\hline L. rhamnosus & LMG 12166 & Topisirovic BGEN1 & Homemade hard cheese \\
\hline L. rhamnosus & LMG 10775 & CCUG 27333, PRSF-L 173 & Human, clinical sample \\
\hline L. rhamnosus & LMG 18030 & El Soda 42, PRSF-L 169 & Zabady (yoghurt) \\
\hline L. rossiae & LMG $22972^{\mathrm{T}}$ & DSM $15814^{\mathrm{T}}$ & Wheat sourdoughs \\
\hline L. ruminis & LMG $10756^{\mathrm{T}}$ & ATCC $27780^{\mathrm{T}}$, DSM $20403^{\mathrm{T}}$ & Bovine, rumen \\
\hline L. ruminis & LMG 11461 & ATCC 27781, DSM 20404 & Bovine, rumen \\
\hline L. saerimneri & LMG $22087^{\mathrm{T}}$ & CCUG $48462^{\mathrm{T}}$, DSM $16049^{\mathrm{T}}$, GDA154 $4^{\mathrm{T}}$ & Pig, faeces \\
\hline L. saerimneri & LMG 22088 & CCUG 48463, DSM 16027, GDA164 & Pig, faeces \\
\hline L. sakei subsp. carnosus & LMG 17305 & CCUG 32077 & Human, blood \\
\hline L. sakei subsp. carnosus & LMG 17306 & CCUG 32584, Kalmar B2571 & Human with endocarditis, blood \\
\hline L. sakei subsp. carnosus & LMG $17302^{\mathrm{T}}$ & CCUG $31331^{\mathrm{T}}$, DSM $15831^{\mathrm{T}}$ & Pig, faeces \\
\hline L. sakei subsp. sakei & LMG $9468^{\mathrm{T}}$ & AS $1.2142^{\mathrm{T}}$, ATCC $15521^{\mathrm{T}}$, CCUG $30501^{\mathrm{T}}$ & Sake starter (Moto) \\
\hline L. sakei subsp. sakei & LMG 7941 & DSM 20198 & \\
\hline L. salivarius & LMG 14476 & Devriese $94 / 438$ & Cat with myocarditis \\
\hline L. salivarius & LMG 14477 & Devriese $94 / 428$ & Parakeet with sepsis \\
\hline L. salivarius subsp. salicinius & LMG $9476^{\mathrm{T}}$ & ATCC $11742^{\mathrm{T}}$, CCUG $39464^{\mathrm{T}}$ & Saliva \\
\hline L. salivarius subsp. salivarius & LMG $9477^{\mathrm{T}}$ & ATCC $11741^{\mathrm{T}}$, DSM $20555^{\mathrm{T}}$ & Saliva \\
\hline L. sanfranciscensis & LMG $16002^{\mathrm{T}}$ & ATCC $27651^{\mathrm{T}}$, DSM $20451^{\mathrm{T}}$ & San Francisco sour dough \\
\hline L. satsumensis & LMG $22973^{\mathrm{T}}$ & & Shochu mashes \\
\hline L. sharpeae & LMG $9214^{\mathrm{T}}$ & ATCC $49974^{\mathrm{T}}$, DSM $20505^{\mathrm{T}}$ & Municipal sewage \\
\hline L. spicheri & LMG $21871^{\mathrm{T}}$ & DSM $15429^{\mathrm{T}}$, LTH $5753^{\mathrm{T}}$ & Rice sourdough \\
\hline L. suebicus & LMG $11408^{\mathrm{T}}$ & ATCC $49375^{\mathrm{T}}$, DSM $5007^{\mathrm{T}}$ & Apple mash \\
\hline L. ultunensis & LMG $22117^{\mathrm{T}}$ & CCUG $48460^{\mathrm{T}}$, DSM $16047^{\mathrm{T}}, \mathrm{Kx} 146 C 1^{\mathrm{T}}$ & Human stomach mucosa \\
\hline L. vaccinostercus & LMG $9215^{\mathrm{T}}$ & ATCC $33310^{\mathrm{T}}$, DSM $20634^{\mathrm{T}}$ & Cow dung \\
\hline L. vaginalis & LMG $12891^{\mathrm{T}}$ & ATCC $49540^{\mathrm{T}}$, DSM $5837^{\mathrm{T}}$ & Vagina \\
\hline L. versmoldensis & LMG $21929^{\mathrm{T}}$ & & Raw fermented sausage \\
\hline L. vitulinus & LMG $18931^{\mathrm{T}}$ & ATCC $27783^{\mathrm{T}}$, DSM $20405^{\mathrm{T}}$ & Calf, rumen \\
\hline L. zeae & LMG $17315^{\mathrm{T}}$ & ATCC $15820^{\mathrm{T}}$, DSM $20178^{\mathrm{T}}$ & Corn steep liquor \\
\hline L. zymae & LMG $22198^{\mathrm{T}}$ & CCM $7241^{\mathrm{T}}$, CCUG $50163^{\mathrm{T}}$ & Wheat sourdough \\
\hline
\end{tabular}

dark bars. The latter only occurs in the rare occasion when, for a given biomarker, members in a taxon are more distant to each other than a member of the taxon is to a member of another taxon. Although not a strict requirement, it is advised that the same OTUs are used for the evaluation of different biomarkers. Missing biomarker data for a given OTU leads to holes in the TaxonGap output matrix. There is no requirement to use the same OTU members for measuring different biomarkers.

Distances used for the calculation of the $s$-heterogeneity and $s$ separability values were determined using pairwise nucleotide sequence alignments with the Needleman-Wunsch algorithm as implemented in the BioNumerics 4.5 software package.

\section{RESULTS AND DISCUSSION}

\section{Application of TaxonGap for the evaluation of pheS and rpoA gene sequences as biomarkers for species identification}

Fig. 2 shows the TaxonGap output for the Lactobacillus identification scheme discussed in the present study. The OTUs subjected to the TaxonGap analysis were the different species of the genus Lactobacillus. Cases where species synonymy has been reported in the literature were regarded as a single species during the TaxonGap analysis. The biomarkers were the pheS, rpoA and 16S rRNA genes. The $s$-heterogeneity is a measure of the heterogeneity observed in the biomarker $s$ among the different strains of the same Lactobacillus species (subsequently referred to as intraspecies heterogeneity). The $s$-separability is a measure of the divergence between the different Lactobacillus species (subsequently referred to as interspecies divergence). Subspecies were not taken into account during this analysis as it was evident from the data that few subspecies could be separated by the biomarkers studied. Where a given gene was able to make clear separation between subspecies, it is indicated in the discussion of the different phylogenetic groups below.

The members of the genus Lactobacillus were ordered according to their phylogenetic positioning in a neighbourjoining tree calculated from the $16 \mathrm{~S}$ rRNA gene sequences of their type strains. The different Lactobacillus species groups are delineated on the left of the neighbour-joining 


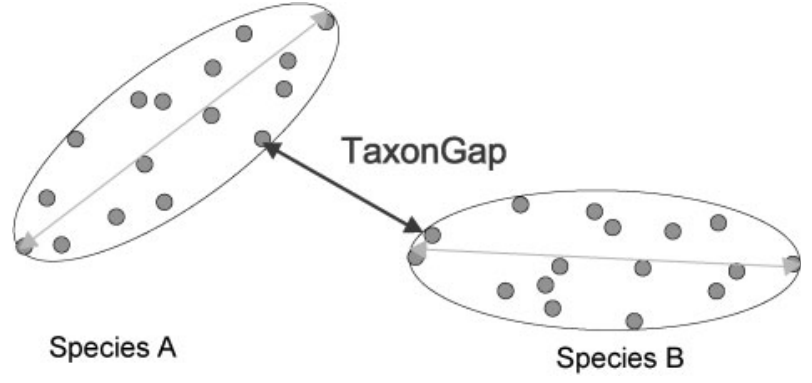

Fig. 1. TaxonGap versus intraspecies diversity. A schematic representation of diversity within and between two species $A$ and B. Dots represent operational taxonomic units (OTUs) in evolutionary space, with the distance between dots relative to the distance derived from sequence information. The intraspecies diversity is indicated by the light grey arrows and represents the maximum sequence distance between strains of the species (corresponds to the light grey bars in Fig. 2). The TaxonGap, indicated by the dark grey arrow, represents the distance between species $A$ and its closest neighbouring species, species $B$ (corresponds to the dark grey bars in Fig. 2).

tree. Although heterogeneity could not be estimated for the $16 \mathrm{~S}$ rRNA gene as sequence data were only available for the type strains, the separability of the Lactobacillus species based on the 16S rRNA gene was added as the first column of the TaxonGap output matrix. This allows better evaluation of the discriminatory power of the 16S rRNA gene for species identification when compared with the other genes included in the identification scheme. The pheS and rpoA genes formed the second and third biomarker columns in the TaxonGap output matrix. In order to guide the readership in the interpretation of the TaxonGap output in the following discussion, we focus on the first row of Fig. 2. From this row, we can determine the $s$ heterogeneity and $s$-separability values for the L. agilis species. For this species, the observed pheS-heterogeneity was $1.5 \%$ (see light grey bar), whereas the $r p o A$ heterogeneity only reached $0.3 \%$ for the same species. Likewise, one can see that the closest neighbour of the $L$. agilis species is estimated differently for the 16S rRNA gene (L. equi; $4.9 \%$ ), the pheS gene (L. animalis; $17.3 \%$ ) and the rpoA gene (L. acidipiscis; $15.7 \%$ ). However, it should be noted that all of these species belong to the same $L$. salivarius species group. This is an example of the general trend observed in the dataset: that when species have different closest neighbours for the genes in the identification scheme, these species all belong to the same species group.

The representation produced by the TaxonGap software tool offers a number of advantages over comparing individual trees for the different gene sequences included in polygenic identification studies. First of all, a separate row is reserved in the TaxonGap output matrix for the heterogeneity and separability values of the different genes for each species, which is not the case when comparing phylogenetic trees. Even after the tedious process of swapping branches, it is not always possible to draw phylogenetic trees in a way that enables clear visual comparisons to be made. This is especially the case when trees for multiple genes need to be compared. In addition, TaxonGap uses the same scaling for depicting the distance values based on the different gene sequences. Few software tools for drawing phylogenetic trees allow precise control over the scaling. Both placement and scaling improve the comparability of the heterogeneity and separability for individual species. Secondly, we want to point out that phylogenetic trees present approximations of the underlying distance values whereas the TaxonGap filters out original similarity values instead of approximations by using minimum and maximum as aggregation operators. This is important when comparing $s$-heterogeneity and $s$ separability for all species for a given gene $s$. To underscore the overall success rate of the individual genes to discriminate between species of the genus Lactobacillus, we have depicted the overall heterogeneity (light grey) and separability (dark grey) per species as vertical lines for each gene in Fig. 2. Finally, the graphical output of TaxonGap remains compact, even for datasets where the number of OTU members grows large. This is because the software has a built-in aggregation based on the individual OTUs. Representing phylogenetic trees with over a few hundred entries would be almost impossible in printed format.

The TaxonGap software tool thus allows for a more straightforward evaluation of the discriminatory power of the individual genes in the Lactobacillus species identification scheme, as opposed to the need to compare separate gene trees drawn for each of the genes in the scheme.

\section{Robustness of pheS and rpoA partial gene sequences for Lactobacillus species identification}

The success of any bacterial species identification system depends on accuracy. Accuracy allows the distinction between intraspecific variation and interspecific divergence in the selected loci. The less overlap there is between genetic variation within species and divergence from species, the more effective the system becomes (Meyer \& Paulay, 2005).

Both the pheS (382-455 nt) and rpoA (402-694 nt) partial gene sequences were applied as alternative genomic markers for the identification of Lactobacillus at the species level. Two hundred and one well-characterized Lactobacillus strains representing 98 species and 17 subspecies of the genus Lactobacillus from different origins were analysed in this study (Table 1). The strains were selected on the basis of previous polyphasic classification using AFLP, RAPD-PCR and SDS-PAGE of whole-cell proteins and represent the known heterogeneity of Lactobacillus species. In order to evaluate the pheS and 
$\underline{15}$

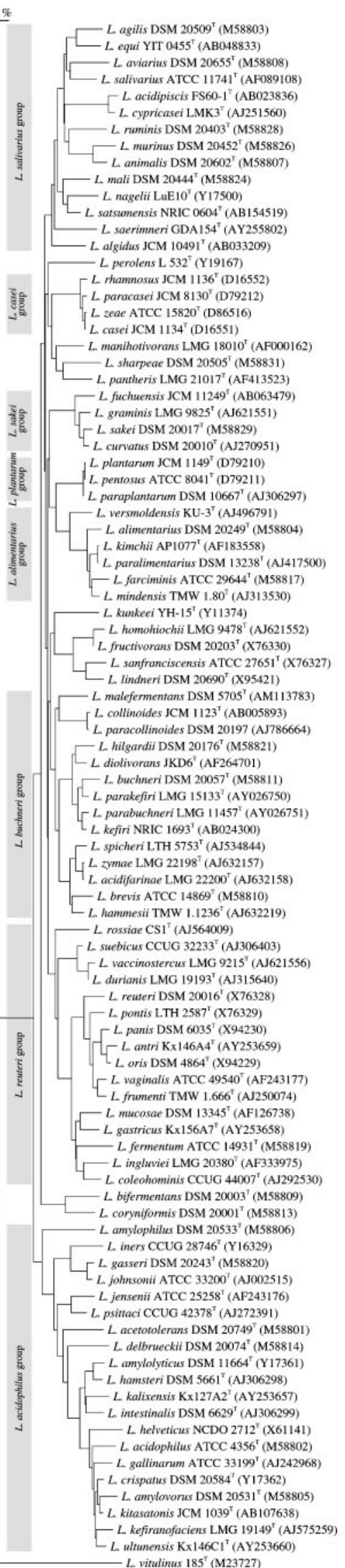

$16 \mathrm{~S}$ rRNA

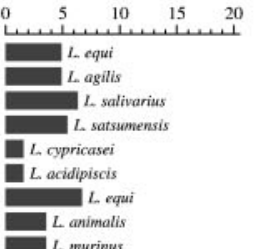

$L$ sarsumensis

$L$ satumensis

L nagelii

$L$ salivarius

L satsumensis

L zeae

I. ree

L zeae

$L$ case

L L zease

$L$ pantheris

$L$ manihorivoran

L curvatus

L. sakei

$L$ curvatus

L sakei

L. pentosus

$L$ plantanem

L. pentosus

L. mindensis

$L$ kimchii

I $L_{\text {paralimentarius }}$

L. kimchii

$L$ mindensis

L. kimchi

$L$ kefiri

$L$ homohiochii

L lindner

L sanfranciscensis

L paracollinoides

I $L$ collinoides

$L$ diolinorans

L parakefiri

$L$ parakefiri

L. panabuchneri

$L$ kefir

1 . parabuclineri

L acidifarinae

L. acidifarinae

L zymae

$L$ hammesii

L acidifarinae

$L$ acidifarinae
$L$ suebicus

$L$ durianis

L durianis

$L$ vaccinostercus

$L$ pontis

1 vaginalis

Loris

Loris

Lontri
$L$ antr

$L$ antri
$L$ frumenti

- $L$ vaginalis

$L$ gastricus

Lucose

$L$ coleohominis

$L$ ingluviei

$L$ inglaviei
$L$ coryniformis

$L$ coryniformis

$L$ bifermentans

$L$ johnsonii

L johnsonii

L gasseri

$L$ gasseri

L psittaci

$L$ intestinalis

$L$ hamster

$L$ hamsteri

L. amylalyricus

$L$ intrestinalis

$L$ amylolyticus

L. amylalyticus
$L$ crisparas

L. crisparas

$L$ crispatus

1 kitasatonis

L tisasents

- $L$ crispatus

L. crispanus

1 kitasatonis phes

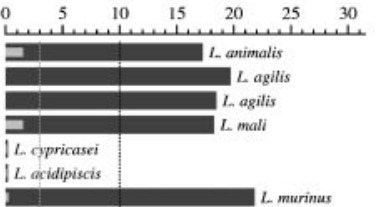

$L$ auimalis

\begin{tabular}{l|l}
$L$ murinus & nagelii \\
\hline
\end{tabular}

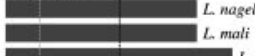

L nagelii

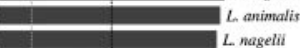

\begin{tabular}{l|l}
\hline nagelii \\
\hline
\end{tabular}

ㄴ. Leae

DI $L$ case

$L$ zene

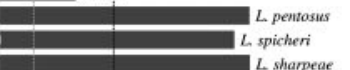

$L$ sakei

L churvatus

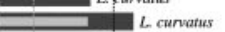

$L$ saminis

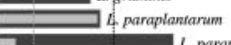

L paraplantane

4. plantanem

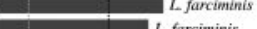

$L$ paralimentarins

$L$ Limchii

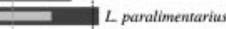

$L$ farciminis

$L$ sanfranciscensis

$L$ fructivorans
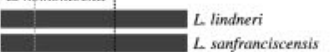

L sanfrantiscenti

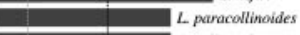

$L$ collinoides

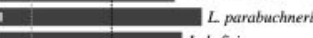

$L_{\text {kefiri }}$

$L$ kefin

ב $\quad$ kefiri

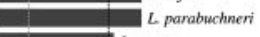

$L$ zymae

L acidifarinae

L sympe

I. parabrevis

L parabrevis
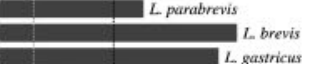

L. durianis

Luaccinostencus
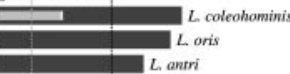

L oris

Lantri

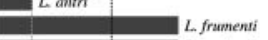

$L$ L framenti
$L$ vaginalis

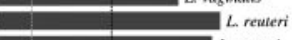

$L$ reuteri

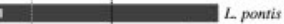

I reuteri

$L_{\text {reuteri }}$
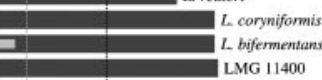

Lenger

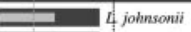

4 johnsoni

L gasseri

$L$. psittaci
L. jensenii

$\left[\begin{array}{l}- \text { kitasatonis } \\ \hline\end{array}\right.$

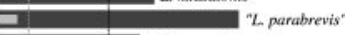

L hamsteri

L amylovones

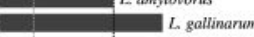

Lamyiovones

$L$ gallipanum

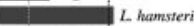

1 helveticus

$L$ gallinarum

ב L kitasatonis

L amylowor

L. hamster
$L$ amyloworus
rpoA

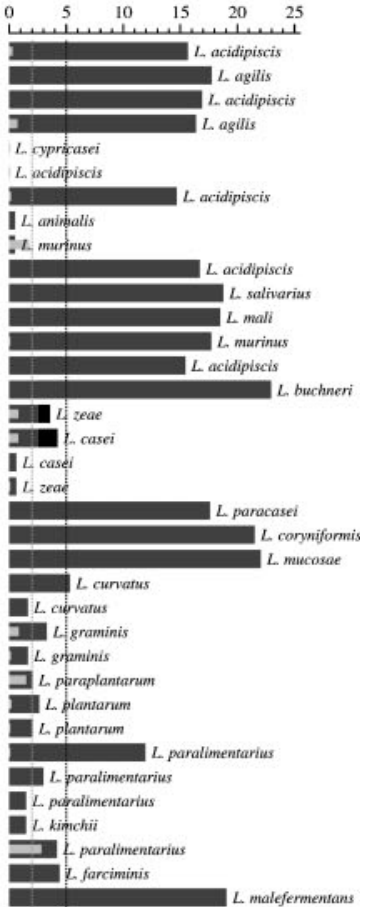

L. fructivorans

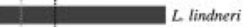

$L$ lindneri
$L$ sanfranciscensis
$L$ collinoides

L paracollinoides

$L$ collinoides

L. diolivorans

$L$ hilgardii

L. parakefiri

L. buchneri

L. kefiri

$L$ buchineri

L. acidifarinae

L. zymae

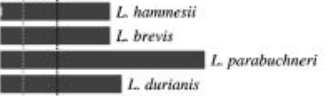

L durianis

L. duriquis

IL. vace hostercus

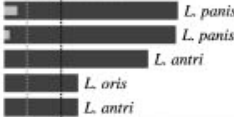

L antr

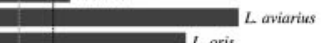

Loris

Lalgidus

$L$ framenti

- $L$ inglavie

$L$ ferment

$L$ oris
$L$ conniformis

II curvatus

1 LMG 11400

L gasseri

בL joghsoni

I L gasseri

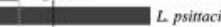

$L_{\text {jensen }}$

$L$ intestinalis

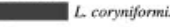

L. hamsteri

$L$ amplolyticus

L hamsteri

$1 L_{\text {gallinanum }}$

$1-$ ultunensis

La he verticus

L kefinanofaciens

kitasatonis

L. kitasatonis 
Fig. 2. Representation of the discriminatory power of the genes for species identification of the genus Lactobacillus. The left panel shows a neighbour-joining tree of the complete 16S rRNA gene sequences of the Lactobacillus type strains, including species groups. EMBL accession numbers of the 16S rRNA gene sequences are indicated in parentheses. For each of the species in the phylogenetic tree, the right panel depicts the intraspecies variability for phe $S$ and $r p o A$ genes and interspecies variability for the $16 \mathrm{~S}$ rRNA, pheS and $r p o A$ genes as horizontal light grey and dark grey bars, respectively. Overall distance gaps between species are represented in the graphic as lines. The right panel also contains the names of the closest relatives as estimated from the different loci.

rpoA gene sequence variations at the intraspecies level, we included several representative strains for each Lactobacillus species. In general, the pheS and rpoA gene sequences showed intraspecies variations up to $3 \%$ and $2 \%$, respectively (Fig. 2 ).

The differentiating power of the pheS and $r p o A$ partial gene sequences was examined for Lactobacillus species at the subspecies level. In general, the subspecies of Lactobacillus were highly related, having $98-100 \%$ pheS and rpoA gene sequence similarities. This shows that the discriminatory power of the investigated loci to differentiate between the subspecies of most lactobacilli is low. However, pheS gene sequences could differentiate between the subspecies of $L$. sakei and L. plantarum (see below).

The analysis of pheS and $r p o A$ partial gene sequences clearly differentiates the members of the genus Lactobacillus (see also Supplementary Figs S1 and S2 available in IJSEM Online). In comparison with the $16 \mathrm{~S}$ rRNA gene, our data clearly indicate that pheS and $r p o A$ genes provide higher resolution for differentiating Lactobacillus species. As shown in Fig. 2, both pheS and rpoA partial gene sequences provide alternative reliable genomic markers to differentiate the members of the genus Lactobacillus. However, it should be mentioned here that both pheS and rpoA partial gene sequences showed a variable discriminatory power for identifying different species of the genus Lactobacillus. An example that illustrates the variation of the pheS and $r p o A$ partial gene sequences in their degree of resolution is shown in Fig. 2 between the type strains of L. acidifarinae and L. zymae (L. buchneri group).

The pheS gene sequence analysis provided the highest discrimination for the identification of different species of lactobacilli. The case of $L$. antri and $L$. oris (L. reuteri group) is an exception here where the rpoA gene provided more resolution than the pheS gene in differentiating the two species. The pheS gene sequence analysis provided an interspecies gap, which normally exceeds $10 \%$ divergence and an intraspecies variation up to $3 \%$. The $r p o A$ gene sequences revealed a somewhat lower resolution with an interspecies gap normally exceeding $5 \%$ and an intraspecies variation up to $2 \%$.

It should be mentioned that the variation of the investigated genes in their discriminatory power, together with the fact that different genes might provide different closest neighbours or topologies without hampering their use to unambiguously circumscribe bacterial species, validated the necessity for the simultaneous analysis of several protein-coding loci for a robust taxonomic analysis at the species and genus levels.

\section{Species groups based on 16S rRNA gene similarity}

The currently recognized phylogenetic relationships within the genus Lactobacillus have been determined by comparative analysis of their 16S rRNA gene sequences (Schleifer \& Ludwig, 1995). Based on these data, different phylogenetic species groups have been distinguished: the $L$. acidophilus, L. reuteri, L. buchneri, $L$. alimentarius, $L$. plantarum, L. sakei, $L$. casei and $L$. salivarius species groups.

On the basis of pheS gene sequence analysis, members of the $L$. reuteri, $L$. alimentarius, $L$. plantarum, $L$. sakei and $L$. casei species groups clustered together in clades corresponding with the 16S rRNA gene based phylogeny (see Supplementary Fig. S1 in IJSEM Online), whereas members of the L. acidophilus, L. buchneri, and L. salivarius species groups are clustered in two separate clades. On the basis of rpoA gene sequence analysis, the $L$. acidophilus, $L$. reuteri, $L$. alimentarius, $L$. plantarum, L. sakei, L. casei and L. salivarius species groups clustered together in clades corresponding with the 16S rRNA gene based phylogeny whereas the $L$. buchneri species group clustered in two separate clades (see Supplementary Fig. S2 in IJSEM Online).

In subsequent sections, we will discuss and compare our data and the data from the literature for all species of the genus Lactobacillus on the basis of the species groups delineated by the 16S rRNA gene phylogeny.

\section{L. acidophilus species group}

Within the L. acidophilus species group, the pheS and rpoA gene sequence data clearly differentiate the members of the L. acidophilus group with a maximum of $94 \%$ and $98 \%$ pheS and rpoA gene sequence similarities, respectively, except for L. kitasatonis and L. amylovorus (with 98.5\% and $99 \%$ pheS and rpoA gene sequence similarities, respectively). At the intraspecies level, strains of same species were highly related $(>98 \%$ pheS and rpoA gene sequence similarities). However, as an exception, the neighbour-joining tree based on phes gene sequences revealed distinct subclusters among strains of the species L. gasseri (8 strains) having $95 \%$ pheS gene sequence similarity and among strains of the species L. johnsonii 
(9 strains) having $96 \%$ phes gene sequence similarity (results not shown). The heterogeneity within L. gasseri strains was also observed by comparing the fluorescent amplified fragment length polymorphism (FAFLP) fingerprints of these strains with reference profiles of lactic acid bacteria taxa (unpublished data).

The neighbour-joining trees derived from the pheS and rpoA gene sequences revealed close relatedness between $L$. helveticus and L. suntoryeus, with at least $99.5 \%$ pheS and rpoA gene sequence similarities (see Supplementary Figs S1 and S2). In addition, sequence analysis of the gene that codes for the $\alpha$-subunit of ATP synthase (atpA) also showed a high relatedness between the two species. Further genomic data derived from DNA-DNA hybridization unambiguously demonstrated that $L$. suntoryeus is a later synonym of L. helveticus (Naser et al., 2006a).

The phes and rpoA partial gene sequences revealed heterogeneity among culture collection strains of $L$. amylophilus described by Nakamura \& Crowell (1979). Strains LMG 11400 and NRRL B-4435 represent a separate lineage that is distantly related to the type strain of $L$. amylophilus LMG $6900^{\mathrm{T}}$ and to three other strains of the species (NRRL B-4438, NRRL B-4439 and NRRL B-4440). The pheS and rpoA gene sequence data showed that strains LMG 11400 and NRRL B-4435 constituted a distinct cluster, showing $100 \%$ pheS and rpoA gene sequence similarities. The other reference strains clustered together with the type strain of L. amylophilus LMG $6900^{\mathrm{T}}$ and were clearly differentiated from strains LMG 11400 and NRRL B-4435 (80\% and $89 \%$ phes and rpoA gene sequence similarities, respectively). Further phenotypic and genotypic research confirmed that both strains represent a novel taxon, for which the name Lactobacillus amylotrophicus has been proposed (Naser et al., 2006b).

\section{L. alimentarius species group}

Within the L. alimentarius group, the pheS gene sequence similarity between $L$. kimchii and L. paralimentarius is $92 \%$, whereas on the basis of $r p o A$ gene sequences, the two species show high relatedness, having $98.5 \%$ rpoA gene sequence similarity. The pheS gene reflects a fast-evolving evolutionary clock that shows a finer resolution than the rpoA gene at both the intraspecies and interspecies levels in most cases. In support of the distinct genomic relatedness between L. kimchii LMG $19822^{\mathrm{T}}$ and L. paralimentarius LMG $19152^{\mathrm{T}}$, De Vuyst et al. (2002) reported a DNA-DNA reassociation value of $68 \%$. Such a hybridization value is considered to be at the borderline for species delineation. The pheS gene sequence data indicates that L. kimchii and L. paralimentarius are separate species.

\section{L. buchneri species group}

Both pheS and rpoA gene sequence analyses showed that the members of L. buchneri species group are clustered in two subclades (see Supplementary Figs S1 and S2). An interesting relationship confirmed by the simultaneous analysis of pheS and rpoA gene sequences is the high genomic relatedness of L. parabuchneri LMG $11457^{\mathrm{T}}$ and $L$. ferintoshensis LMG $22038^{\mathrm{T}}$ (100\% pheS and rpoA gene sequence similarities). Recently published data are in complete accordance with the pheS and $r p o A$ gene sequence data. Vancanneyt et al. (2005) confirmed this finding and demonstrated that these taxa are synonymous species, based on a polyphasic study.

Representative strains of L. brevis, LMG $6906^{\mathrm{T}}$, LMG 11435, LMG 7761, LMG 11494 and LMG 11984, were investigated. The pheS gene sequence analysis showed that strains LMG 11494 and LMG 11984 constituted a distinct cluster separated from the type strain of $L$. brevis with a sequence similarity of less than $82 \%$ (see Supplementary Figs S1 and S2). 16S rRNA gene sequence analysis showed that both strains belong to the L. buchneri group with nearest neighbours $L$. hammesii and $L$. brevis (sequence similarities of 99.2 and $98.1 \%$, respectively). Strains LMG 11494 and LMG 11984, isolated from cheese and wheat, respectively, showed $99.9 \%$ pheS gene sequence similarity. It has recently been confirmed that both strains represent a novel taxon, for which the name $L$. parabrevis was proposed (Vancanneyt et al., 2006).

\section{L. casei species group}

Difficulties in the accurate identification of species belonging to the $L$. casei species group have been reported (Tynkkynen et al., 1999; Zhong et al., 1998). A study by Mori et al. (1997) found high 16S rRNA gene sequence similarity between the members of $L$. casei species group (>99\%). In the present study, L. rhamnosus, L. casei and L. paracase $i$ were clearly distinguished on the basis of pheS and $r p o A$ genes. Apart from L. casei and L. zeae (see below), these species have a maximum of $84 \%$ and $95 \%$ pheS and $r p o A$ gene sequence similarities, respectively. This result further emphasizes the discriminatory power of the housekeeping genes investigated in this study.

Within the $L$. casei species group, the pheS gene sequence similarity between L. casei LMG $6904^{\mathrm{T}}\left(=\right.$ ATCC $\left.393^{\mathrm{T}}\right)$ and L. zeae LMG $17315^{\mathrm{T}}\left(=\right.$ ATCC $158520^{\mathrm{T}}$ ) was $93 \%$, whereas on the basis of $r p o A$ gene sequences, the two species were more highly related, having $99 \%$ gene sequence similarity. In addition, the sequence analysis of the gene that codes for the $\alpha$-subunit of ATP synthase (atpA) also showed a high relatedness (96\%) between the two species (data not shown). Data from the literature were in complete accordance with the present data and supported the high relatedness found between these two taxa. Further genomic data derived from $r e c A$ gene sequence analysis and high DNA-DNA reassociation values $(80 \%)$ demonstrated that both species are members of the same species (Dicks et al., 1996; Felis et al., 2001) and supported the reclassification of $L$. casei as $L$. zeae (Dellaglio et al., 2002). This example strongly supports the simultaneous use of multiple loci. 


\section{L. plantarum species group}

16S rRNA gene sequences are not suitable for definitive differentiation of the members of $L$. plantarum species group due to the high gene sequence similarity (>99\%) between $L$. plantarum, $L$. paraplantarum and $L$. pentosus (Collins et al., 1991; Torriani et al., 2001). Our data clearly showed that pheS and rpoA gene sequences had a high discriminatory power in differentiating $L$. plantarum, $L$. paraplantarum and L. pentosus with a maximum $90 \%$ and $98 \%$ pheS and rpoA gene sequence similarities, respectively. At the subspecies level, the neighbour-joining tree based on the pheS gene sequences showed that $L$. plantarum subsp. plantarum and L. plantarum subsp. argentoratensis were clearly differentiated from each other $(91 \%$ pheS gene sequence similarity) (see Supplementary Fig. S1). $L$. plantarum LMG $6907^{\mathrm{T}}$ and L. arizonensis LMG $19807^{\mathrm{T}}$ were highly related with $>99.5 \%$ pheS and rpoA gene sequence similarity. Kostinek et al. (2005) showed that $L$. arizonensis is a later heterotypic synonym of $L$. plantarum because the type strain of $L$. arizonensis NRRL B- $14768^{\mathrm{T}}$ $\left(=\mathrm{DSM} 13273^{\mathrm{T}}\right)$ is not distinguishable from the $L$. plantarum type strain DSM $20174^{\mathrm{T}}$ on the basis of ribotyping patterns, rep-PCR fingerprinting patterns, $16 \mathrm{~S}$ rRNA gene sequences or DNA-DNA hybridization data.

\section{L. reuteri species group}

Within this species group, high degrees of similarity exist between L. ingluviei LMG $20380^{\mathrm{T}}$ and L. thermotolerans LMG $22056^{\mathrm{T}}(99 \%$ and $100 \%$ phes and rpoA gene sequence similarities, respectively) as well as between $L$. durianis LMG $19193^{\mathrm{T}}$ and L. vaccinostercus $\mathrm{LMG} 9215^{\mathrm{T}}$ ( $99 \%$ and $98 \%$ pheS and rpoA gene sequence similarities, respectively). A study recently conducted by Felis et al. (2006) confirmed that $L$. thermotolerans is a later synonym of $L$. ingluviei. Representative strains of $L$. durianis and $L$. vaccinostercus were further investigated. Genomic data derived from FAFLP and DNA-DNA hybridizations, respectively, has provided evidence for the reclassification of L. durianis as L. vaccinostercus (Dellaglio et al., 2006).

On the other hand, the neighbour-joining tree based on pheS gene sequences revealed heterogeneity between strains of $L$. reuteri. As mentioned earlier, the pheS gene reflects a fast-evolving evolutionary clock that shows a finer resolution, in most cases, than the rpoA gene at both the intraspecies and interspecies levels.

\section{L. sakei species group}

L. sakei and L. curvatus have $>99 \% 16 \mathrm{~S}$ rRNA gene sequence similarity; the corresponding pheS and rpoA gene sequence similarities were $88 \%$ and $96 \%$. At the subspecies level, the neighbour-joining tree based on the pheS gene sequences showed that $L$. sakei subsp. sakei and $L$. sakei subsp. carnosus were clearly differentiated from each other ( $92 \%$ pheS gene sequence similarity) (see Supplementary Fig. S1).

\section{L. salivarius species group}

The pheS neighbour-joining tree split this species group into two subclusters (see Supplementary Fig. S1). An interesting relationship detected by the simultaneous analysis of phes and rpoA gene sequences is the high genomic relatedness of the $L$. cypricasei and $L$. acidipiscis type strains. L. acidipiscis strains (LMG $19820^{\mathrm{T}}$ and LMG 23135) and the strains of L. cypricasei (LMG $21592^{\mathrm{T}}$, CCUG 42959, CCUG 42960 and CCUG 42962) revealed 99.8-100\% pheS and rpoA gene sequence similarities. Sequence analysis of the atpA gene also showed a high relatedness $(>99 \%)$ between the two species (data not shown). High DNA-DNA reassociation values confirmed that $L$. cypricasei is a later synonym of $L$. acidipiscis (Naser et al., 2006c).

In addition, whereas the type strains of $L$. animalis and $L$. murinus are separated by their $16 \mathrm{~S}$ rRNA gene sequences, these two species are highly related on the basis of their pheS and rpoA gene sequences (Fig. 2). The type strains of $L$. animalis and $L$. murinus occupied a distinct subcluster having $98.5 \%$ pheS and rpoA gene sequence similarities.

\section{Other Lactobacillus species}

The type strains of $L$. fructivorans and $L$. homohiochii showed a high degree of similarity $(100 \%$ pheS and rpoA gene sequence similarities). Further taxonomical studies are needed to clarify their relatedness.

\section{Conclusions}

It is now generally accepted that a correct classification should reflect the natural relationships as encoded in the DNA and consequently genotypic methods are considered of paramount importance to modern taxonomy. The use of several housekeeping genes in bacterial taxonomy is best suited for analysis at the species and genus levels as it integrates the information of different molecular clocks around the bacterial chromosome (Gevers et al., 2005; Stackebrandt et al., 2002; Zeigler, 2003).

Our data convincingly prove that the simultaneous analysis of pheS and rpoA partial gene sequences provide an alternative tool for the rapid and reliable identification of different species of the genus Lactobacillus. The analysis of pheS and rpoA gene sequences effectively allows closely related Lactobacillus species to be differentiated at a higher discrimination level than that possible with 16S rRNA gene sequence comparisons.

The fact that within species groups, different genes may yield different tree topologies does not hamper their use to unambiguously assign isolates to a particular species. Several factors account for the different topologies determined for different housekeeping genes, i.e. the level of the information content, the different rates of evolution due to different selection forces on various genes and the length of the partial sequences that are compared 
(Christensen et al., 2004). The variation in the discriminatory power of the investigated genes, together with the fact that different genes might provide different closest neighbours or tree topologies, has highlighted the necessity for simultaneous analysis of several protein-coding loci for a robust identification analysis.

We intend to contribute to the present identification system by the construction of a central, curated database in which data can be stored and accessed freely online. This is expected to contribute in the long run to the improvement of a better species definition for the genus Lactobacillus. The system is rapid, highly reproducible, portable and provides adequate resolution power. In addition, we further intend to extend this system to include all other genera of LAB.

\section{ACKNOWLEDGEMENTS}

S.M.N. acknowledges a $\mathrm{PhD}$ scholarship from the Ministry of Education and Higher Education, Palestine. J.S. and D. G. acknowledge grants from the Fund for Scientific Research (FWO), Belgium. We thank Leentje Christiaens and Marjan De Wachter for their technical assistance.

\section{REFERENCES}

Christensen, H., Kuhnert, P., Olsen, J. E. \& Bisgaard, M. (2004). Comparative phylogenies of the housekeeping genes atpD, infB, rpoB and the 16S rRNA gene within the Pasteurellaceae. Int J Syst Evol Microbiol 54, 1601-1609.

Coenye, T., Gevers, D., Van de Peer, Y., Vandamme, P. \& Swings, J. (2005). Towards a prokaryotic genomic taxonomy. FEMS Microbiol Rev 29, 147-167.

Collins, M. D., Rodrigues, U., Ash, C., Aguirre, M., Farrow, J. A. E., Martinez-Murcia, A., Phillips, B. A., Williams, A. M. \& Wallbanks, S. (1991). Phylogenetic analysis of the genus Lactobacillus and related lactic acid bacteria as determined by reverse transcriptase sequencing of 16S rRNA. FEMS Microbiol Lett 77, 5-12.

Daud Khaled, D., Neilan, B. A., Henriksson, A. \& Conway, P. L. (1997). Identification and phylogenetic analysis of Lactobacillus using multiplex RAPD-PCR. FEMS Microbiol Lett 153, 191-197.

De Vuyst, L., Schrijvers, V., Paramithiotis, S., Hoste, B., Vancanneyt, M., Swings, J., Kalantzopoulos, G., Tsakalidou, E. \& Messens, W. (2002). The biodiversity of lactic acid bacteria in Greek traditional wheat sourdoughs is reflected in both composition and metabolite formation. Appl Environ Microbiol 68, 6059-6069.

Dellaglio, F., Felis, G. E. \& Torriani, S. (2002). The status of the species Lactobacillus casei (Orla-Jensen 1916) Hansen and Lessel 1971 and Lactobacillus paracasei Collins et al. 1989. Request for an opinion. Int J Syst Evol Microbiol 52, 285-287.

Dellaglio, F., Vancanneyt, M., Endo, A, Vandamme, P., Felis, G. E., Castioni, A., Fujimoto, J., Watanabe, K. \& Okada, S. (2006). Lactobacillus durianis Leisner et al. 2002 is a later heterotypic synonym of Lactobacillus vaccinostercus Kozaki and Okada 1983. Int J Syst Evol Microbiol 56, 1721-1724.

Dicks, L. M., Du Plessis, E. M., Dellaglio, F. \& Lauer, E. (1996). Reclassification of Lactobacillus casei subsp. casei ATCC 393 and Lactobacillus rhamnosus ATCC 15820 as Lactobacillus zeae nom. rev., designation of ATCC 334 as the neotype of L. casei subsp. casei, and rejection of the name Lactobacillus paracasei. Int J Syst Bacteriol 46, 337-340.

Felis, G. E., Dellaglio, F., Mizzi, L. \& Torriani, S. (2001). Comparative sequence analysis of a recA gene fragment brings new evidence for a change in the taxonomy of the Lactobacillus casei group. Int J Syst Evol Microbiol 51, 2113-2117.

Felis, G. E., Vancanneyt, M., Snauwaert, C., Swings, J., Torriani, S. \& Castioni, A.andDellaglio, F. (2006). Reclassification of Lactobacillus thermotolerans Niamsup et al. 2003 as a later synonym of Lactobacillus ingluviei Baele et al. 2003. Int J Syst Evol Microbiol 56, 793-795.

Gancheva, A., Pot, B., Vanhonacker, K., Hoste, B. \& Kersters, K. (1999). A polyphasic approach towards the identification of strains belonging to Lactobacillus acidophilus and related species. Syst Appl Microbiol 22, 573-585.

Gevers, D., Huys, G. \& Swings, J. (2001). Applicability of rep-PCR fingerprinting for identification of Lactobacillus species. FEMS Microbiol Lett 205, 31-36.

Gevers, D., Cohan, F. M., Lawrence, J. G., Spratt, B. G., Coenye, T., Feil, E. J., Stackebrandt, E., Van de Peer, Y., Vandamme, P. \& other authors (2005). Opinion: re-evaluating prokaryotic species. Nat Rev Microbiol 3, 733-739.

Hammes, W. P. \& Vogel, R. F. (1995). The genus Lactobacillus. In The Genera of Lactic Acid Bacteria, pp. 19-54. Edited by B. J. B. Wood \& W. H. Holzapfel. London: Blackie Academic \& Professional.

Holzapfel, W. H., Haberer, P., Geisen, R., Bjorkroth, J. \& Schillinger, U. (2001). Taxonomy and important features of probiotic microorganisms in food and nutrition. Am J Clin Nutr 73, 365S-373S.

Kandler, O. \& Weiss, N. (1986). Genus Lactobacillus Beijerinck 1901, 212. In Bergey's Manual of Systematic Bacteriology, vol. 2, pp. 1209-1234. Edited by P. H. A. Sneath, N. S. Mair \& J. G. Holt. Baltimore, USA: The Williams and Wilkins Co.

Klein, G., Pack, A., Bonaparte, C. \& Reuter, G. (1998). Taxonomy and physiology of probiotic lactic acid bacteria. Int J Food Microbiol 41, 103-125.

Konstantinidis, K. T. \& Tiedje, J. M. (2005). Towards a genome-based taxonomy for prokaryotes. J Bacteriol 187, 6258-6264.

Kostinek, M., Pukall, R., Rooney, A. P., Schillinger, U., Hertel, C., Holzapfel, W. H. \& Franz, C. M. A. P. (2005). Lactobacillus arizonensis is a later heterotypic synonym of Lactobacillus plantarum. Int J Syst Evol Microbiol 55, 2485-2489.

Massi, M., Vitali, B., Federici, F., Matteuzzi, D. \& Brigidi, P. (2004). Identification method based on PCR combined with automated ribotyping for tracking probiotic Lactobacillus strains colonizing the human gut and vagina. J Appl Microbiol 96, 777-786.

Meyer, C. P. \& Paulay, G. (2005). DNA barcoding: error rates based on comprehensive sampling. PLoS Biol 3 (e422).

Mori, K., Yamazaki, K., Ishiyama, T., Katsumata, M., Kobayashi, K., Kawai, Y., Inoue, N. \& Shinano, H. (1997). Comparative sequence analyses of the genes coding for 16S rRNA of Lactobacillus caseirelated taxa. Int J Syst Bacteriol 47, 54-57.

Nakamura, L. K. \& Crowell, C. D. (1979). Lactobacillus amylophilus, a new starch-hydrolyzing species from swine waste-corn fermentation. Dev Ind Microbiol 20, 532-540.

Naser, S., Thompson, F. L., Hoste, B., Gevers, D., Vandemeulebroecke, K., Cleenwerck, I., Thompson, C. C., Vancanneyt, M. \& Swings, J. (2005a). Phylogeny and identification of enterococci using atpA gene sequence analysis. J Clin Microbiol 43, 2224-2230.

Naser, S. M., Thompson, F. L., Hoste, B., Gevers, D., Dawyndt, P., Vancanneyt, M. \& Swings, J. (2005b). Application of multilocus sequence analysis (MLSA) for rapid identification of Enterococcus species based on rpoA and pheS genes. Microbiology 151, 2141-2150. 
Naser, S. M., Hagen, K. E., Vancanneyt, M., Cleenwerck, I., Swings, J. \& Tompkins, T. A. (2006a). Lactobacillus suntoryeus Cachat and Priest 2005 is a later synonym of Lactobacillus helveticus (Orla-Jensen 1919) Bergey et al. 1925 (Approved Lists 1980). Int J Syst Evol Microbiol 56, 355-360.

Naser, S. M., Vancanneyt, M., Snauwaert, C., Vrancken, G., Hoste, B. De Vuyst, L. \& Swings, J. (2006b). Reclassification of Lactobacillus amylophilus LMG 11400 and NRRL B-4435 as Lactobacillus amylotrophicus sp. nov. Int J Syst Evol Microbiol 56, 2523-2527.

Naser, S. M., Vancanneyt, M., Hoste, B., Snauwaert, C. \& Swings, J. (2006c). Lactobacillus cypricasei Lawson et al. 2001 is a later synonym of Lactobacillus acidipiscis Tanasupawat et al. 2000. Int J Syst Evol Microbiol 56, 1681-1683.

Niemann, S., Puhler, A., Tichy, H. V., Simon, R. \& Selbitschka, W. (1997). Evaluation of the resolving power of three different DNA fingerprinting methods to discriminate among isolates of a natural Rhizobium meliloti population. J Appl Microbiol 82, 477-484.

Pot, B., Hertel, C., Ludwig, W., Descheemaeker, P., Kersters, K. \& Schleifer, K. H. (1993). Identification and classification of Lactobacillus acidophilus, L. gasseri and L. johnsonii strains by SDSPAGE and rRNA-targeted oligonucleotide probe hybridization. J Gen Microbiol 139, 513-517.

Reid, G. (1999). The scientific basis for probiotic strains of Lactobacillus. Appl Environ Microbiol 65, 3763-3766.

Saitou, N. \& Nei, M. (1987). The neighbour-joining method: a new method for reconstructing phylogenetic trees. Mol Biol Evol 4, 406-425.

Santos, S. R. \& Ochman, H. (2004). Identification and phylogenetic sorting of bacterial lineages with universally conserved genes and proteins. Environ Microbiol 6, 754-759.

Schleifer, K. H. \& Ludwig, W. (1995). Phylogeny of the genus Lactobacillus and related genera. Syst Appl Microbiol 18, 461-467.

Sneath, P. H. A. \& Sokal, R. R. (1973). Numerical Taxonomy. The Principles and Practice of Numerical Classification. San Francisco: W. H. Freeman and Co.

Stackebrandt, E., Frederiksen, W., Garrity, G. M., Grimont, P. A., Kämpfer, P., Maiden, M. C., Nesme, X., Rossello-Mora, R., Swings, J.
\& other authors (2002). Report of the ad hoc committee for the reevaluation of the species definition in bacteriology. Int J Syst Evol Microbiol 52, 1043-1047.

Stiles, M. E. \& Holzapfel, W. H. (1997). Lactic acid bacteria of foods and their current taxonomy. Int J Food Microbiol 36, 1-29.

Thompson, F. L., Gevers, D., Thompson, C. C., Dawyndt, P., Naser, S., Hoste, B., Munn, C. B. \& Swings, J. (2005). Phylogeny and molecular identification of vibrios on the basis of multilocus sequence analysis. Appl Environ Microbiol 71, 5107-5115.

Torriani, S., Felis, G. E. \& Dellaglio, F. (2001). Differentiation of Lactobacillus plantarum, $L$. pentosus, and $L$. paraplantarum by recA gene sequence analysis and multiplex PCR assay with $\operatorname{rec} A$ genederived primers. Appl Environ Microbiol 67, 3450-3454.

Tynkkynen, S., Satokari, R., Saarela, M., Mattila-Sandholm, T. \& Saxelin, M. (1999). Comparison of ribotyping, randomly amplified polymorphic DNA analysis, and pulsed-field gel electrophoresis in typing of Lactobacillus rhamnosus and L. casei strains. Appl Environ Microbiol 65, 3908-3914.

Vancanneyt, M., Engelbeen, K., De Wachter, M., Vandemeulebroecke, K., Cleenwerck, I. \& Swings, J. (2005). Reclassification of Lactobacillus ferintoshensis as a later heterotypic synonym of Lactobacillus parabuchneri. Int J Syst Evol Microbiol 55, 2195-2198.

Vancanneyt, M., Naser, S. M., Engelbeen, K., De Wachter, M., Van der Meulen, R., Cleenwerck, I., Hoste, B., De Vuyst, L. \& Swings, J. (2006). Reclassification of Lactobacillus brevis LMG 11494 and LMG 11984 as Lactobacillus parabrevis sp. nov. Int J Syst Evol Microbiol 56, 1553-1557.

Yansanjav, A., Svec, P., Sedlacek, I., Hollerova, I. \& Nemec, M. (2003). Ribotyping of lactobacilli isolated from spoiled beer. FEMS Microbiol Lett 229, 141-144.

Zeigler, D. R. (2003). Gene sequences useful for predicting relatedness of whole genomes in bacteria. Int J Syst Evol Microbiol 53, 1893-1900.

Zhong, W., Millsap, K., Bialkowska-Hobrzanska, H. \& Reid, G. (1998). Differentiation of Lactobacillus species by molecular typing. Appl Environ Microbiol 64, 2418-2423. 